CLINICAL STUDY

\title{
The reduction of bone mineral density in postmenopausal women with primary hyperparathyroidism is higher in the presence of concomitant GH secretion impairment
}

\author{
Elisabetta Cecconi, Maurizio Gasperi, Maura Genovesi, Fausto Bogazzi, Lucia Grasso, Filomena Cetani, \\ Massimo Procopio ${ }^{1}$, Claudio Marcocci, Luigi Bartalena ${ }^{2}$ and Enio Martino \\ Department of Endocrinology and Metabolism, University of Pisa, Ospedale, Cisanello, Via Paradisa 2, 56124 Pisa, Italy, ${ }^{1}$ Division of Endocrinology, \\ University of Turin, Turin, Italy and ${ }^{2}$ Chair and Division of Endocrinology, University of Insubria, 21100 Varese, Italy \\ (Correspondence should be addressed to M Gasperi; Email: mgasperi@endoc.med.unipi.it)
}

\begin{abstract}
Objective: To investigate, in a large group of postmenopausal primary hyperparathyroidism (PHP) women, whether the concomitance of GH deficiency (GHD) may contribute to the development of changes in bone mineral density (BMD).

Design: GH secretion, bone status and metabolism were investigated in 50 postmenopausal women with PHP and in a control group of 60 women with no evidence of PHP, matched for age, age at menopause and body mass index (BMI).

Methods: GH response to growth hormone-releasing hormone (GHRH) + arginine (Arg), femoral neck $\operatorname{BMD}\left(\mathrm{g} / \mathrm{cm}^{2}\right)$ by dual energy X-ray absorptiometry, BMI, serum-ionized calcium, parathyroid hormone (PTH) and markers of bone remodelling were evaluated in all patients and controls.

Results: Among PHP patients, GH secretion was reduced $(8.8 \pm 4.2 \mu \mathrm{g} / \mathrm{l}$, range $1.1-16.5 \mu \mathrm{g} / \mathrm{l})$ in 34 patients and normal $(28.7 \pm 11.8 \mu \mathrm{g} / \mathrm{l}$, range $17.9-55.7 \mu \mathrm{g} / \mathrm{l})$ in the remaining $16(P<0.05)$, no women in the control group had GHD (peak GH $33.8 \pm 10.9 \mu \mathrm{g} / \mathrm{l}$, range $21.7 \pm 63.2 \mu \mathrm{g} / \mathrm{l}$ ). Osteoporosis (T-score $<-2.5$ ) and osteopenia (T-score $>-2.5$ and $<-1$ ) were found in 73.5 and $17.6 \%$ of GHD patients, in 37.5 and $43.7 \%$ of patients with normal GH secretion and 3.1 and $27 \%$ of controls. T-score and BMD were not correlated with ionized calcium, age, age at menopause, BMI, GH peak and IGF-I but were correlated with serum PTH levels in both groups. T-score was correlated with serum levels of markers of bone remodelling only in PHP patients with GHD.

Conclusions: Concomitant impairment of GH secretion may play a pathogenetic role in the occurrence of changes in bone mass observed in PHP and contribute to make them more severe.
\end{abstract}

European Journal of Endocrinology 155 41-45

\section{Introduction}

It is well established that primary hyperparathyroidism (PHP), due to excessive parathyroid hormone (PTH) secretion usually by a parathyroid adenoma, is responsible for changes in bone metabolism leading to a reduction in bone mineral density (BMD) (1-4). We recently reported that many patients with untreated PHP due to parathyroid adenoma have an impaired growth hormone (GH) secretion, as assessed by a blunted GH response to maximal stimulation by growth hormone-releasing hormone (GHRH) + arginine (Arg) test and by the assessment of $24-\mathrm{h} \mathrm{GH}$ secretion $(5,6)$. Improvement of GH deficiency (GHD) is achieved in PHP patients after parathyroidectomy (7). The observation that a reduced GH response to provocative stimuli is found in members of families with familial hypocalciuric hypercalcemia (FHH), whose serum PTH levels are normal, underscores the concept that hypercalcemia rather than increased PTH is likely the factor responsible for GHD in PHP (8), as confirmed by the observation that no abnormality of $\mathrm{GH}$ secretion was found in secondary hyperparathyroidism (9). Both childhood-onset and adult-onset GHD show a reduction in BMD, which improves following GH replacement therapy (10-12). Thus, both conditions (PHP and GHD) have negative effects on bone mass.

The aim of the present study was to investigate, in a large group of postmenopausal PHP women, whether the concomitance of GHD may contribute to the development of changes in BMD.

\section{Patients and methods}

\section{Subjects}

Fifty consecutive PHP postmenopausal women (mean age $62.5 \mathrm{yr}$, range $48-85$, body mass index (BMI) $26 \pm$ 0.2 ) referred to our Institution during 4 years were 
enrolled in this study. PHP was in all cases due to a single parathyroid adenoma. Diagnosis was based on the increase in serum total and ionized calcium and PTH levels, and supported by the presence of a hypoechoic posterior nodule in the thyroid bed by ultrasonography, and by a positive sestamibi parathyroid scan. No patients had history of head trauma; pituitary magnetic resonance imaging was normal in all patients. No clinical and biochemical thyroid, adrenal and gonadal dysfunction, as well as renal, liver and cardiac abnormalities were found. No patients were taking drugs known to affect $\mathrm{GH}$ secretion or bone mineral metabolism, including estroprogestins. Sixty postmenopausal women matched for age, age at menopause, BMI served as controls (Table 1).

The study was approved by the local ethical committee, and all patients provided their informed consent.

\section{Assays}

Serum ionized calcium, PTH, GH, insulin-like growth factor-I (IGF-I) were measured as previously reported $(5,6)$. Stimulated GH secretion was evaluated after i.v. administration of GHRH + Arg, as previously reported $(5,6)$. Briefly, serum GH concentrations were measured at baseline and 30,60 , and $90 \mathrm{~min}$ after the simultaneous i.v. 30-min infusion of Arg hydrochloride $(0.5 \mathrm{~g} / \mathrm{kg}$ body weight) and GHRH $(1 \mu \mathrm{g} / \mathrm{kg}$ body weight as an i.v. bolus at $0 \mathrm{~min}$; GHRH-29, Geref, Serono). Blood samples for basal hormone measurements and stimulation tests were carried out at $0800 \mathrm{~h}$, after an overnight fast. GH measurements were carried out in a single run for each patient; serum GH assay

Table 1 Clinical and biochemical features of PHP and control postmenopausal women.

\begin{tabular}{lccc}
\hline & \multicolumn{2}{c}{ PHP } & \\
\cline { 2 - 3 } & GHD & No GHD & Controls \\
\hline Patients (No.) & 34 & 16 & 60 \\
Age (yr) & $62.3 \pm 8.4$ & $62.3 \pm 9.9$ & $63 \pm 8.7$ \\
Age of & $50.8 \pm 2.4$ & $51.4 \pm 2.2$ & $51.1 \pm 3.2$ \\
menopause (yr) & & & \\
BMl & $25.9 \pm 1.8$ & $26.3 \pm 1.7$ & $26.1 \pm 1.5$ \\
Ca $^{++}(\mathrm{nmol} / \mathrm{l})$ & $1.51 \pm 0.13$ & $1.48 \pm 0.10$ & $1.24 \pm 0.4^{* *}$ \\
PTH $(\mathrm{pg} / \mathrm{ml})$ & $188.1 \pm 124.9$ & $136.9 \pm 59.3$ & $48.3 \pm 15.6^{\star *}$ \\
T-score & $-2.4 \pm 1.6$ & $-2.0 \pm 1.0$ & $-1.0 \pm 0.4^{* *}$ \\
B-ALP $(\mu \mathrm{g} / \mathrm{l})$ & $28.5 \pm 2.3$ & $19.2 \pm 19$ & $16.8 \pm 8.3^{* *}$ \\
OC $(\mu \mathrm{g} / \mathrm{l})$ & $36.6 \pm 27.3$ & $35.6 \pm 24$ & $18.7 \pm 10.5^{\star *}$ \\
S-CTX pM/l & $5580.7 \pm 4073$ & $8808.4 \pm 7751$ & $3502 \pm 1120^{\star *}$ \\
Peak GH & $8.8 \pm 4.2 \dagger$ & $28.7 \pm 11.8$ & $32.6 \pm 7.8^{*}$ \\
(ng/ml)\# & & & \\
IGF-I (ng/ml) & $134.7 \pm 60.8$ & $126.0 \pm 41.7$ & $170.8 \pm 78.3$ \\
\hline
\end{tabular}

Data are expressed as mean \pm s.D. Normal values: $\mathrm{Ca}^{++} 1.13-1.30 \mathrm{mmol} / \mathrm{l}$, PTH 10-65 pg/ml, B-ALP 2-28 $\mu \mathrm{g} / \mathrm{l}$, OC $6.8-34 \mu \mathrm{g} / \mathrm{l}, \mathrm{S}-\mathrm{CTX}<4520 \mathrm{pM} / \mathrm{l}$, IGF-I age $>50$ yr $71-290 \mu \mathrm{g} / \mathrm{l}$. \#Mean peak GH values after $\mathrm{GHRH}+\mathrm{Arg}$ Q1 stimulation. $+P<0.05 \mathrm{GHD}$ vs no GHD patients. ${ }^{*} P<0.05$ controls vs $\mathrm{GHD}$ patients. ${ }^{\star *} P<0.05$ controls vs both GHD and no GHD patients.
(RIAs, Nichols Institute Diagnostics, San Clemente, CA, USA) had a sensitivity of $0.15 \mu \mathrm{g} / \mathrm{l}$; sensitivity of IGF-I assay (RIAs, Nichols Institute Diagnostics, San Clemente, CA, USA) was $0.3 \mu \mathrm{g} / \mathrm{l}$. Inter- and intraassay coefficients of variation were: $2.9-4.5$ and $2.4-4 \%$ for $\mathrm{GH}$ and $7.6-15.5$ and $10.1-15.7 \%$ for IGF-I respectively. Bone-specific alkaline phosphatase (B-ALP) was measured by specific IRMA (Tandem-R Ostase, Beckman Coulter, San Diego, CA, USA); interand intra-assay coefficients of variation were: 3.7-6.7 and $7-8.1 \%$ respectively; osteocalcin (OC) by IRMA (Osteo-RIACT, Cis Bio International, Yvette Cedex, France); inter- and intra-assay coefficients of variation were: $1.2-2.8$ and $3.6-5.2 \%$ respectively, serum cross-laps (S-CTX) by ELISA (Osteometer Bio Tech, Herlev, Denmark); inter- and intra-assay coefficients of variation were: $5.1-5.4$ and $6.5-8.1 \%$ respectively.

Normal values in our laboratory were as follows: serum ionized calcium, 1.13-1.30 mmol/l; serum PTH, 10-65 pg/ml; serum IGF-I, $182-780 \mu \mathrm{g} / \mathrm{l}, 16-24 \mathrm{yr}$, 90-492 $\mu \mathrm{g} / \mathrm{l}, 25-50 \mathrm{yr}, 71-290 \mu \mathrm{g} / \mathrm{l},>50 \mathrm{yr}$, B-AlP Q3 $2-28 \mu \mathrm{g} / \mathrm{l}$, OC $6.8-34 \mu \mathrm{g} / \mathrm{l}, \mathrm{S}-\mathrm{CTX}<4520 \mathrm{pM} / \mathrm{l}$.

In our laboratory, the lower value of peak serum GH after GHRH + Arg test in a group of normal subjects comparable for sex and age was $16.5 \mu \mathrm{g} / \mathrm{l}$ as previously reported $(13,14)$.

BMD was evaluated by dual energy X-ray absorptiometry (Hologic 4500 Elite, Hologic Inc., Waltham, MA, USA). BMD was measured in gram per centimeter square and expressed also as T-score. According to World Health Organization (WHO, 1994), definition regarding postmenopausal women, T-score values $<-2.5$ were considered osteoporotic, between -1 and -2.5 osteopenic and $T$-score $>-1$ normal.

\section{Statistical analysis}

Data were reported as mean \pm s.D.; differences for quantitative variables of patients were evaluated using ANOVA for repeated measures; differences for qualitative variables were measured by unpaired tests.

\section{Results}

Based on GH response to GHRH + Arg stimulation test, PHP patients were subdivided into two groups (Table 1): 34 patients had a blunted GH response (mean $8.8 \pm$ $4.2 \mu \mathrm{g} / \mathrm{l}$, range $1.1-16.5 \mu \mathrm{g} / \mathrm{l}$ ) indicating the presence of concomitant GHD (PHP-GHD); the remaining 16 patients had a normal GH response (mean 28.7 \pm $11.8 \mu \mathrm{g} / \mathrm{l}$, range $17.9-55.7 \mu \mathrm{g} / \mathrm{l}, P<0.0001$ vs PHP with GHD) suggestive of normal GH secretion (PHP-no GHD). Mean GH values after GHRH + Arg in controls were significantly higher than those in PHP-GHD $(P<0.0001)$, but not different from PHP-no GHD (Table 1). No difference was found between the two groups for age, age at menopause, BMI, serum ionized calcium, PTH and IGF-I concentrations. 
Mean T-score was not statistically different between the two groups of PHP patients $(-2.4 \pm 1.2$ in PHPGHD vs $-2.05 \pm 1.01$ in PHP-no GHD); however, osteoporosis (T-score $<-2.5$ ) and osteopenia (T-score $>-2.5$ and $<-1$ ) were found in 73 and $18 \%$ of PHPGHD respectively, in 37 and $44 \%$ of PHP-no GHD respectively, and in 3 and $27 \%$ of controls respectively (Figs 1 and 2). The prevalence of osteoporosis in PHPGHD was significantly higher than in PHP-no GHD patients $(P=0.02)$ and controls (Table 2, $P=0.02)$. The cumulative prevalence of bone mass reduction (osteoporosis + osteopenia) was $91 \%$ in PHP-GHD, $81 \%$ in PHP-no GHD $(P=N S)$ vs $30 \%$ in controls $(P=0.02)$. $T$-score was correlated with serum PTH levels $(P=0.02)$ and not with ionized calcium, age, age at menopause, BMI, GH peak and IGF-I. Mean BMD was not statistically different between the two groups of PHP patients $\left(0.77 \pm 0.14 \mathrm{~g} / \mathrm{cm}^{2}\right.$ in PHP-GHD vs $0.82 \pm$ 0.14 in PHP-no GHD) and was correlated only with serum PTH $(P=0.05)$.

T-score was correlated with markers of bone remodelling only in GHD patients (Fig. 3). Serum concentrations of markers of bone remodelling were increased in $42 \%$ (B-ALP), 54\% (OC), and 67\% (S-CTX) of PHP patients. However, as illustrated in Table 1 , while mean values of each parameter in PHP-GHD and PHP-no GHD were significantly higher than in controls, no significant differences between the two groups of PHP patients were observed.

\section{Discussion}

The results of the present study demonstrate that PHP patients with concomitant GH deficiency (PHP-GHD) have a higher prevalence of osteoporosis than PHP patients without GHD patients (PHP-no GHD). The latter, in turn, have a higher prevalence of osteoporosis than controls. On the other hand, the prevalence of osteopenia is higher in PHP-no GHD than in PHP-GHD;

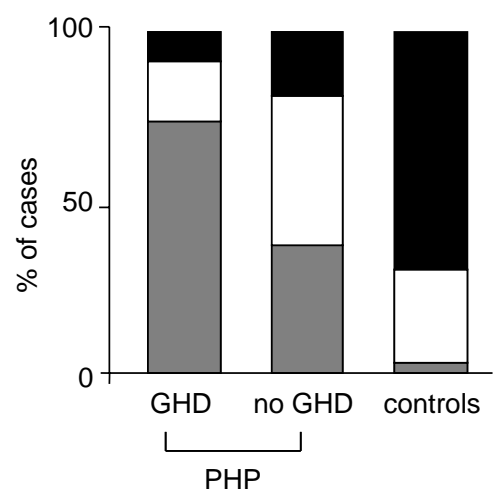

Figure 1 Prevalence of osteoporosis $(\square)$, osteopenia $(\square)$ and normal bone density $(\boldsymbol{\square})$ in patients with hyperparathyroidism with associated GH deficiency (GHD), without GHD (no GHD), and in controls. For significance of differences, see text.

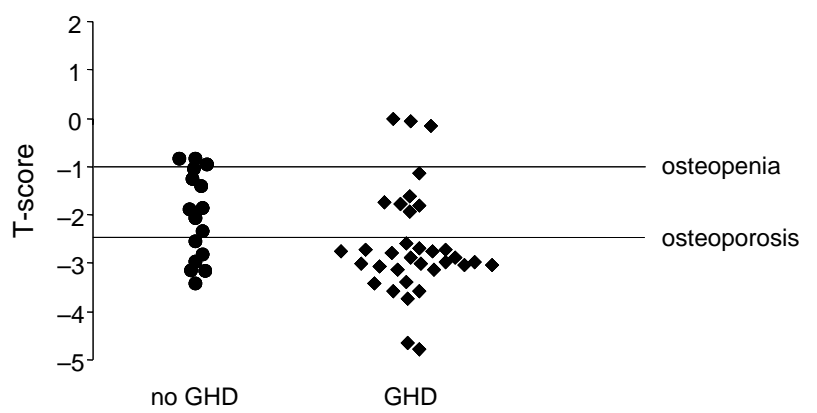

Figure $2 T$-score values in patients with hyperparathyroidism with associated GH deficiency (GHD) and without GHD (no GHD).

thus, cumulating the two different degrees of bone mass reduction (osteoporosis and osteopenia), differences between the two groups attenuate, although changes are clearly more severe in PHP patients in whom the increase in PTH secretion is accompanied by an impairment in $\mathrm{GH}$ secretion.

Bone remodelling is regulated by a balance between bone resorption and bone formation (15). When the former prevails, osteoporosis develops, as in PHP. The adverse effects of PHP on bone are of special concern in postmenopausal women (15). As a matter of fact, osteoporosis has recently become the major factor in the process of prescribing therapy in asymptomatic PHP and the BMD threshold for recommending surgery has been increased (15).

GH has profound effects on linear bone growth, bone metabolism and bone mass (10). GH plays a crucial role in the maintenance of bone mass in adults by regulating bone remodelling through a complex interaction of circulating GH, IGF-I, IGF binding protein (IGFBP) factors and locally produced IGF and IGFBP acting in an autocrine and paracrine way (16). In vitro $\mathrm{GH}$ stimulates osteoclastic bone resorption through direct and indirect actions on osteoclast differentiation and through indirect activation of mature osteoclasts, possibly via local IGF-I/II production from osteoblasts (17). Unfortunately, at present locally produced IGF-I cannot be evaluated and therefore we think it is not possible to differentiate in vivo $\mathrm{GH}$ and IGF-I actions.

Adult patients with GHD have decreased bone mineral content and BMD, the severity of which is related to the timing, age of onset and severity of GHD $(12,18)$. An increased prevalence of osteoporosis has been found in several studies of patients with adultonset GHD (18). Patients with isolated GHD had similar

Table 2 The patients GHD present a significantly higher incidence of osteoporosis.

\begin{tabular}{lrccc}
\hline & GHD & No GHD & Total & $\chi^{2}$ \\
\hline Patients with osteoporosis & 25 & 6 & 31 & 0.02 \\
Patients without osteoporosis & 9 & 10 & 19 & NS \\
Total & 34 & 16 & 50 & \\
\hline
\end{tabular}



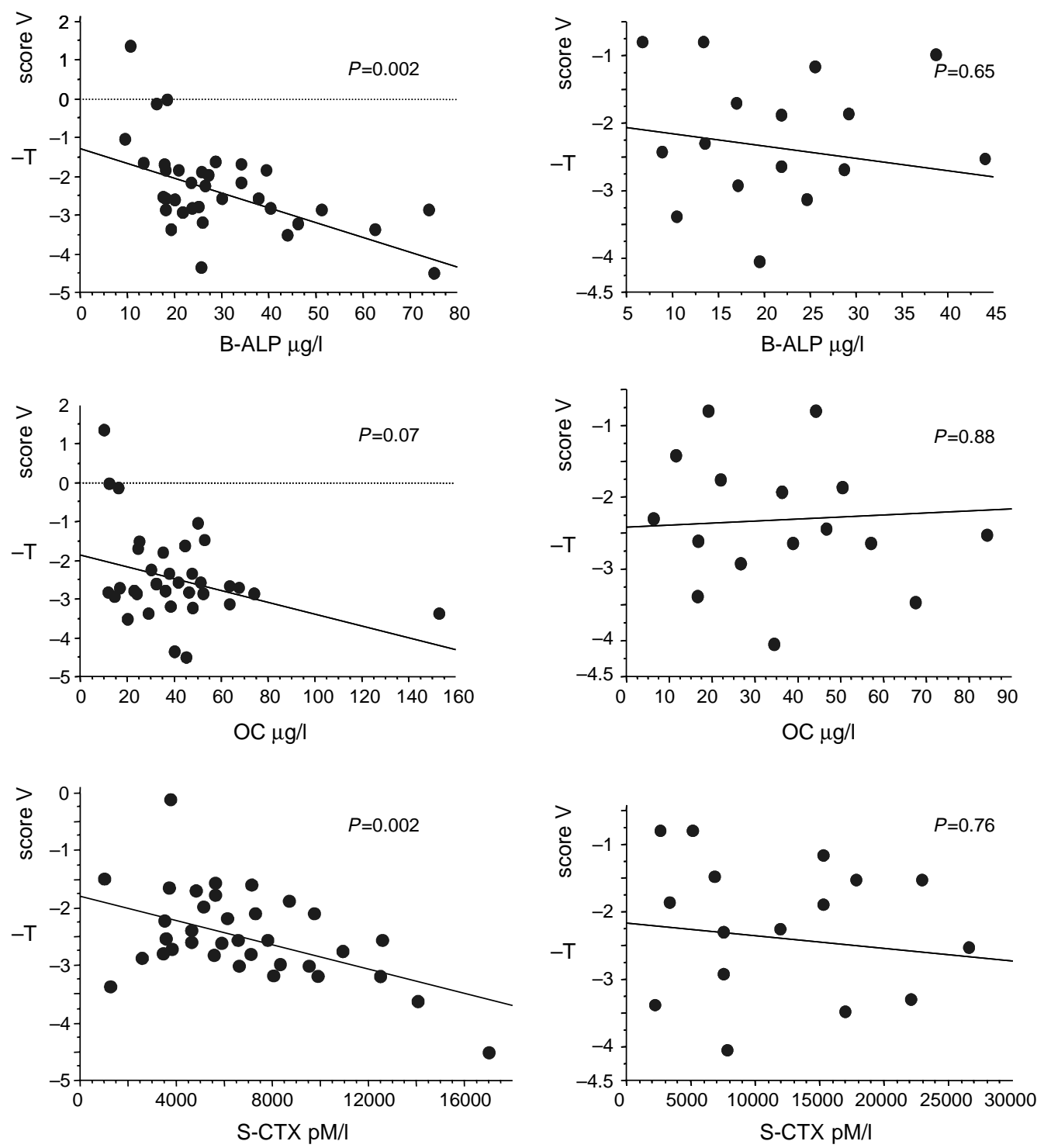

Figure 3 Correlation between $T$-score values and serum concentrations of markers of bone remodelling in patients with hyperparathyroidism with associated GH deficiency (GHD) (A) or without GHD (B).

prevalence of fractures to those with multiple pituitary hormone deficiencies $(12,18)$. GH replacement therapy can improve BMD in these patients (19).

As we previously reported, PHP is a condition often associated with functional GHD (5); the latter can be reverted by surgically removing parathyroid adenoma(s) responsible for PHP (7). Hypercalcemia rather than the increase in serum PTH seems to account for the development of GHD, as shown by our recent studies in two families with FHH (8). The results of the present study suggest that the combination of PHP and GHD in postmenopausal women seems to have an additive effect in bone remodelling, even if a direct effect of GHD status on T-score and/or BMD could not be demonstrated. It is difficult to speculate on the possible mechanisms involved in the process in vivo. The use of bone turnover markers is controversial (20-22). In fact, while in postmenopausal women, there is a correlation between bone turnover markers and BMD (23), in the same patients B-ALP and short-term changes in collagen cross-links during therapy are important predictive factors in bone mass recovery (23). OC as a marker of bone formation and deoxypiridinoline, bone resorption, are increased in the majority of PHP patients, denoting a high rate of bone turnover with persistent coupling between formation and resorption $(1,2)$. On the other hand, no conclusive data are available on the effects of GHD on bone remodelling in adults. Serum levels of OC, reflecting osteoblast activity and bone formation have been found to be decreased, increased or unchanged 
$(10,11)$. Most studies have shown that there is no difference in resorption markers between controls and adult GHD patients (12).

In our PHP of patients, in many instances serum levels of all markers were increased, in keeping with the literature (1-3). Moreover, no difference was found between GHD and no GHD patients; however, a significant correlation was demonstrated between $T$-score and each of the biochemical markers only in the subgroup of $\mathrm{GHD}$ patients. It seems, therefore, that lack of $\mathrm{GH}$ could be an important factor in influencing the degree of bone mass loss.

In conclusion, an impairment of $\mathrm{GH}$ secretion, frequently concomitant with PHP and due to hypercalcemia, could be involved as a pathogenic factor in the abnormalities of bone metabolism accompanying PHP. The more severe degree of bone mass reduction observed in the presence of GHD should represent an additional indication for a definitive resolution of PHP by surgery, avoiding further delay or postponing.

\section{Acknowledgements}

This work was partially supported by Grants from the University of Pisa (Fondi di Ateneo) and M.I.U.R., Rome to Enio Martino, from the University of Pisa and from Ministry of Education, University and Research (M.I.U.R., Rome) to Maurizio Gasperi, and from the University of Insubria at Varese to Luigi Bartalena.

\section{References}

1 Silverberg SJ \& Bilezikian JP. Clinical presentation of primary hyperparathyroidism in the United States. In The Parathyroids: Basic and Clinical Concepts. 2nd edn, pp. 349-360, New York: Academic Press, 2001.

2 Silverberg SJ \& Bilezikian JP. Clinical course of primary hyperparathyroidism in the United States. In The Parathyroids: Basic and Clinical Concepts. 2nd edn, pp. 387-398, New York: Academic Press, 2001.

3 Silverberg SJ. Natural history of primary hyperparathyroidism. Endocrinology Metabolism Clinics of North America 200029 451-464.

4 Seibel MJ. Molecular markers of bone metabolism in parathyroid disease. In The Parathyroids: Basic and Clinical Concepts. 2nd edn, pp. 399-409, New York: Academic Press, 2001.

5 Gasperi M, Cecconi E, Grasso L, Bartalena L, Centoni R, Aimaretti G, Broglio F, Miccoli P, Marcocci C, Ghigo E \& Martino E. GH secretion is impaired in patients with primary hyperparathyroidism. Journal of Clinical Endocrinology and Metabolism 200287 1961-1964.

6 Cecconi E, Gasperi M, Grasso L, Genovesi M, Amaretti G, Broglio F, Bartalena L, Marcocci C \& Martino E. Primary hyperparathyroidism is associated with an impaired secretion of growth hormone but not of the other anterior pituitary hormones. Journal of Endocrinological Investigation 200225 RC7-RC9.

7 Cecconi E, Gasperi M, Bogazzi F, Grasso L, Genovesi M, Marcocci C, Pinchera A, Procopio M, Bartalena L \& Martino E. Improvement of growth hormone deficiency in patients with primary hyperparathyroidism after parathyroidectomy: results of a prospective study. Journal of Clinical Endocrinology and Metabolism 200489 1213-1216.

8 Cecconi E, Bogazzi F, Cetani F, Grasso L, Marcocci C, Genovesi M, Procopio M, Gasperi M, Pinchera A, Ghigo E \& Martino E. Impaired GH secretion to provocative stimuli in two families with hypocalciuric hypercalcaemia. Clinical Endocrinology 200359 604-606.

9 Cecconi E, Gasperi M, Genovesi M, Bogazzi F, Grasso L, Procopio M, Marcocci C, Pinchera A, Bartalena L \& Martino E. Growth hormone secretion in primary and secondary hyperparathyroidism. Journal of Endocrinological Investigation 200528 113-116.

10 Ohlsson C, Bengtsson B, Isaksson OGP, Andreassen TT \& Slootweg MC. Growth hormone and bone. Endocrine Reviews $19981955-79$.

11 Doga M, Bonadonna S, Gola M, Mazziotti G, Nuzzo M \& Giustina A. $\mathrm{GH}$ deficiency in the adult and bone. Journal of Endocrinological Investigation 200528 18-23.

12 Wuster C, Bengtsson B, Bennmarker H, Feldt-Rasmussen U, Hernberg-Stahl E, Monson JP, Westberg B, Wilton P and on behalf of the kims study group and the kims international board. The influence of growth hormone deficiency, growth hormone replacement therapy and other aspect of hypopituitarism on fracture rate and bone mineral density. Journal of Bone and Mineral Research $200116398-405$.

13 Aimaretti G, Corneli G, Razzore P, Bellone S, Baffoni C, Arvat E \& Ghigo E. Comparison between insulin-induced hypoglycemia and Growth Hormone (GH)-Releasing Hormone + Arginine provocative tests for the diagnosis of $\mathrm{GH}$ deficiency adults. Journal of Clinical Endocrinology and Metabolism 199883 1615-1624.

14 Valetto MR, Bellone J \& Baffoni C. Reproducibility of the growth hormone response to stimulation with growth hormonereleasing hormone plus arginine during lifespan. European Journal Endocrinology 1986135 568-572.

15 Cormier C, Souberbielle JC \& Kahan A. Primary hyperparathyroidism and osteoporosis in 2004. Joint Bone Spine 2004 71 183-189.

16 Thor Ueland. Bone metabolism in relation to alterations in systemic growth hormone. Growth Hormone and IGF Research 200414 404-417.

17 Thor Ueland. GH/IGF-I and bone resorption in vivo and in vitro. European Journal of Endocrinology 2005152 327-332.

18 Colao A, Di Somma C, Pivonello R, Loche S, Aimaretti G, Cerbone G, Faggiano A, Corneli G, Ghigo E \& Lombardi G. Bone loss is correlated to the severity of growth hormone deficiency in adult patients with hypopituitarism. Journal of Clinical Endocrinology and Metabolism 199984 1919-1924.

19 Biermasz NR, Neveen A, Hamdy NAT, Pereira AM, Romijn JA \& Roelfsema F. Long-term skeletal effects of recombinant human growth hormone (rhGH) alone and rhGH combined with alendronate in GH-deficients adults: a seven-year follow-up study. Clinical Endocrinology 200460 568-575.

20 Seibel MJ. Biochemical markers of bone metabolism in the assessment of osteoporosis: Useful or not? Journal of Endocrinological Investigation 200326 464-471.

21 Stepan JJ. Clinical utility of bone markers in the evaluation and follow-up of osteoporotic patients: Why are the markers poorly accepted by clinicians? Journal of Endocrinological Investigation $20036458-463$.

22 Rodriguez-Arnao J, James I, Jabbar A, Trainer PJ, Perrett D, Besser GM \& Ross J. Serum collagen cross links as markers of bone turnover during GH replacement therapy in growth hormone deficient adults. Clinical Endocrinology $1998 \mathbf{4 8} 455-462$.

23 Delmas PD. Markers of bone turnover for monitoring treatment of osteoporosis with antiresorptive drugs. Osteoporosis International $20006566-576$.

Received 28 December 2005

Accepted 7 April 2006 